\title{
Research on Problems of Hospital Infections after Operation and Nursing Management in Operating Room
}

\author{
Dandan Yang ${ }^{1, a}$ \\ ${ }^{1}$ Luohe Medical College, Luohe, Henan, China, 462000 \\ ${ }^{a}$ email
}

Keywords: Spinal Operation, Hospital Infections, Nursing in Operating Room

\begin{abstract}
Objective: Taking the spinal surgery as an example, we investigate the related factors of hospital infections with aseptic operation and strengthen the management of operation room nursing to reduce the incidence of hospital infections in operation room. Methods: The questionnaire was used to collect personal data of health emergency personnel in The First Affiliated Hospital of Luohe Medical College from January of 2012 to December $21^{\text {st }}$ of 2015 . Results: 21 cases of spinal surgery aseptic surgery infection and type of surgery, hospital location, operation site, operation time, whether the surgery, preoperative use of antibiotics, postoperative urine leading factors closely related to the operation room. Conclusion: A series of nursing intervention measures can be taken to reduce the incidence of nosocomial infection in the surgical department of spine surgery.
\end{abstract}

Operation room is an important place for the hospital to implement surgical treatment and take the rescue work, the nursing work and the patient's life is closely related. With the development of anesthesia, surgical equipment, surgical equipment is increasing, to carry out continuous operations, the traditional operation room nursing management model of hospital infection control for the poor is more and more prominent. Spinal surgery is more than repair or reconstruction surgery, postoperative hospital infection, can cause serious complications. In order to understand the related factors of hospital infection in operation room nursing in our hospital in patients with spinal surgery, to take corresponding control measures, reduce the incidence of nosocomial infection, the author of the spine surgery in our hospital twenty-one cases of surgical hospital infection patients were analyzed retrospectively. They were reported as follows now.

\section{Object and Method}

General Information. The general data of January 2012 in spinal surgery the First Affiliated Hospital of our school in December 2015 for a spinal surgery aseptic operation in 950 cases, according to the clinical manifestations of postoperative wound healing and diagnosed 21 cases of nosocomial infections. Among them, there are 13 male cases and 8 female cases; age from 52 to 73 years, average 65 years old.

Method. Twenty-one cases of incision infection case investigation, consulting and operation related information, such as the type of surgery, surgical site, surgical site, surgical time, surgery, preoperative application of antibiotics, postoperative urinary operation room leading factors and visitors, and a comprehensive analysis of the data.

Statistical Method. We use the SPSS 13 U statistical software. The data was be analyzed by $\mathrm{x}$ 士, $\mathrm{t}$ test and PGO. U5 represents for there were significant differences. 


\section{Results (Table 1.)}

Table 1. Relationship between hospital infections after operation and operation room related factors

\begin{tabular}{|c|c|c|c|}
\hline related factors & $\begin{array}{l}\text { number of } \\
\text { total cases }\end{array}$ & $\begin{array}{l}\text { number of } \\
\text { infectious cases }\end{array}$ & percent \\
\hline \multicolumn{4}{|l|}{ surgical site } \\
\hline cervical & 310 & 8 & 2.28 \\
\hline thoracic & 245 & 4 & 1.63 \\
\hline lumbar & 395 & 9 & 2.28 \\
\hline \multicolumn{4}{|l|}{ surgical time } \\
\hline$>3 \mathrm{~h}$ & 435 & 13 & 2.99 \\
\hline$\ll 3 h$ & 515 & 8 & 1.55 \\
\hline \multicolumn{4}{|l|}{ continuous operation } \\
\hline yes & 425 & 12 & 2.82 \\
\hline no & 525 & 9 & 1.71 \\
\hline \multicolumn{4}{|l|}{$\begin{array}{l}\text { use antibiotics } 30 \text { minutes } \\
\text { before surgery }\end{array}$} \\
\hline yes & 650 & 11 & 1.85 \\
\hline no & 300 & 10 & 2 \\
\hline \multicolumn{4}{|l|}{ visitors } \\
\hline yes & 250 & 11 & 4.4 \\
\hline no & 700 & 10 & 1.43 \\
\hline \multicolumn{4}{|l|}{$\begin{array}{l}\text { catheterization before } \\
\text { operation }\end{array}$} \\
\hline yes & 600 & 15 & 2.5 \\
\hline no & 350 & 6 & 1.71 \\
\hline
\end{tabular}

\section{Reasons Analysis and Countermeasures}

The management of hospital infection in operation room has a direct impact on the operation of medical safety, and the quality of medical treatment is the guarantee of the quality of surgical care. With the continuous improvement of medical quality, the development of surgical techniques in spinal surgery change rapidly, common hospital infection factors include: (1) endogenous: the misuse of antibiotics, leading to low immunity disease and other reasons; (2) exogenous (cross infection): the patient and the environment, disease and the patient, patient and medical staff, patients and accompanying visitors; (3) iatrogenic: invasive operation (surgery, puncture, catheterization, placement of the instrument body etc.). The most common infection factors associated with surgery include: the operation of medical staff in the process of aseptic operation is in place; in the use of equipment and operation for sterilization is qualified; the surgical choice is correct; whether the appropriate surgical patients undergoing operation room; the indoor environment is not compliance; after the operation began implementation of isolation measures are in place. The traditional operation room nursing management attention work nurses, hospital infection management in contempt, that the management of hospital infection is limited to disinfection and isolation; disinfection and isolation work but also pay attention to disinfection, isolation and contempt; in the above link there is great hidden trouble. 
Management of Operating Room. Operation room safety environment disinfection can be up to the standard, but the work is not in place, resulting in disinfection of indoor environment pollution is soon. Such as the beginning of the operation, the doors and windows are not tight. The air cleanliness by disinfection machine cannot be maintained. To strengthen the isolation of the operation room and operation room door separate electric door; the door carts, cars and shuttle patients increase surgical gown; use surgical brush hands and clothes and restricted area slippers for one use a disinfection or sterilization; all patients by the cart shuttle, and make a clear distinction between the use of internal and external cart. Can achieve the purpose of isolation, but also can improve the quality of service, to avoid

Medical security risks; adjust the layout of the operation room, open 3 channels (patients, staff, use), not reflux. At the same time, improve the monitoring of sterilization of equipment, so as to meet the requirements of the national legal standards.

Due to the different internal configuration of the operation, the excessive use of the operation room, resulting in the disinfection of the indoor environment cannot achieve satisfactory results; there is a risk of hospital infection. This retrospective study found that the incidence rate of nosocomial infection was $2.82 \%$, and the incidence rate of non-contact surgery was $1.71 \%$, which indicated that there was a higher incidence rate of hospital infection.

Air pollution by operation environment is the main source of exogenous bacteria cultivation during operation. This study shows that the laminar flow operation room infection rate and no visit of the surgical infection rate is low, this is because the laminar flow operation room can effectively reduce the indoor concentration of bacteria, reduce the risk of infection; and strictly control the number of visitors operation, it can effectively reduce the flow of air pollution. It is reported that the number of bacteria in the operation room landing have changed significantly during the operation, at the beginning of land is the largest, one peak appeared at the end of this movement is the main factors of air pollution in the operation room. The nurse must be in operation before the operation of all items need to be in operation into the interior, a variety of operating action should be gentle, and reduce the patient changes. Strictly control the number of visitors, as far as possible to reduce indoor walking or from a room to another room, must not be allowed to go to the Department of orthopedics from infection operating room operating room, "maintain a distance of $30 \mathrm{~cm}$ visitors and doctors.

Sterilization of various surgical items is also the key to prevent infection of the incision. Should choose the correct sterilization method, and combined with scientific monitoring means, to ensure that the effect of sterilization. The heat and humidity, high temperature resistant equipment, dressings should be used for pressure steam sterilization and other items also try to use such as epoxy ethane, low-temperature plasma sterilization, the use of the principle of strict implementation of a one-time items. For the expected operation is complex, time is estimated to be more than 3h, as far as possible in the first stage, the use of laminar flow surgery, reducing the number of times the number of times. The operation room should be restricted to other personnel in and out of the surgery, in order to reduce the staff to move around. The operation of the following table must comply with the principle of first aseptic bacteria. We should strictly control the items such as equipment, packaging bags, patients taking coat in order to reduce the pollution of the operation room.

Personnel Matching in Operating Room. In the course of medical treatment of spinal surgery in our hospital, the existing nursing staff in the operation room is in full load condition. From the perspective of medical quality management, emphasize the synergism of depletion of numbers, a certain number of personnel is a reliable guarantee for the quality of medical care. 4 additional 
nursing personnel, training of qualified posts, complete and prolong the operation time and prolong the operation time and with no understanding in the management of hospital infection in operation room. We should master the maintenance process and maintenance of spinal surgery commonly used equipment, excluding small troubleshooting methods of knowledge and skills, so as to eliminate the small fault during the. We should establish the surgical equipment inspection and registration system, surgical equipment, personnel management, regular inspection and registration to ensure that the instrument is in good condition and to reduce the possibility of failure.

\section{References}

[1] Kahn JS. , Clinical Microbiology Reviews, Vol. 17 (2006) No19, p. 546-557.

[2] Weigl JAI, Puppe W, Meyer CU, et al., European Journal of Pediatrics, Vol. 91 (2007) No1, p.669-966

[3] Williams JV, Wang C'K, Yang C'F, et al., Journal of Infectious Diseases, Vol. 34 (2006) No193, p.387-395

[4] Sloots TP,Mackay M,Kevinet al., Emerging Infectious Diseases, Vol.75(2006)No12, p.1263-1266

[9] Uerna U, C'ampanini U, Rovido F, et al., Archives of Virology, Vol.150 (2005) No12, p.2365-2375.

[5] WoII DU,Ureenberg D,Kalkstein D,et al., Pediatric Infectious Diseases Journal, Vol.56 (2006) No25, p. 320-324.

[6] Uarcia\}Iarcia MI, Calvo, Perez-Brena P, et al., Pediatric Pulmonology, Vol.41 (2006) No2, p.863-871. 